\section{Critical Visions}
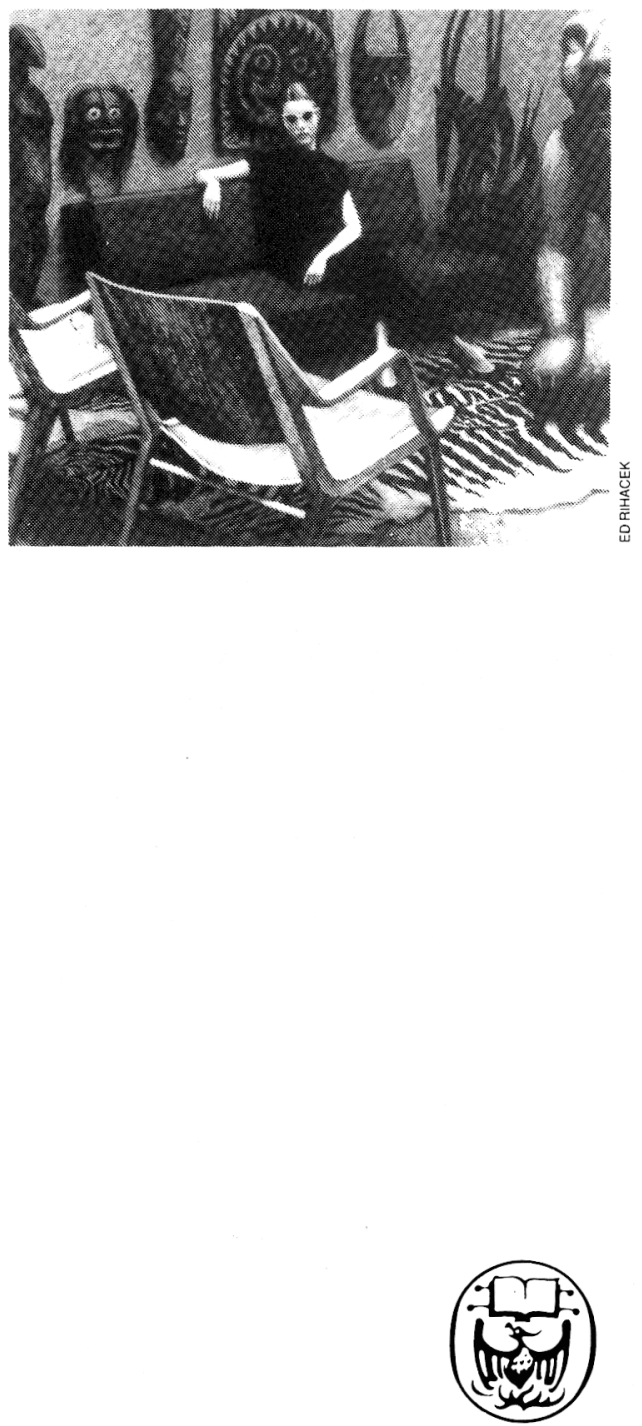

\section{THE UNIVERSITY OF CHICAGO PRESS}

5801 SOUTH ELLIS AVENUE CHICAGO, IL 60637

At bookstores, or call: 1-800-621-2736 In Illinois: 312-568-1550

\section{Gone Primitive}

Savage Intellects, Modern Lives

\section{Marianna Torgovnick}

This far-reaching work of cultural criticism explores the obsessions, fears, and longings that have produced Western views of the primitive.

"A superb book. . . a kind of gift to its own culture, a guide to the perplexed. It is lucid, usually fair, laced with a certain feminist mockery and animated by some surprising sympathies." -Arthur C. Danto, New York Times Book Review Cloth $\$ 24.95340$ pages

1 color plate, 34 halftones

\section{Erotic Faith}

Being in Love from Jane Austen

to D. H. Lawrence

\section{Robert M. Polhemus}

In this major study of love and fiction, Polhemus approaches novelists' faith in love through erotic and religious themes in the work of artists including Botticelli, Vermeer, Redon, and Klimt.

"A sensitive, deeply insightful, even moving study of sexual passion in major novels and works of art. "-Anne K. Mellor

Cloth \$29.95 396 pages

8 color plates, 10 halftones

\section{The Rule of Art}

Literature and Painting in the Renaissance Clark Hulse

Hulse charts the relationship of poetry and painting in fifteenth- and sixteenth-century Europe, examining the theoretical language in which such major figures as.Alberti, Raphael, Castiglione, Sidney, and Hilliard defined the connections between the arts.

"Hulse has a genuine gift for elucidation and synthesis, and a striking sense of relevance. This is in every sense an important, original work." -Stephen Orgel

Cloth $\$ 32.50240$ pages 43 halftones 


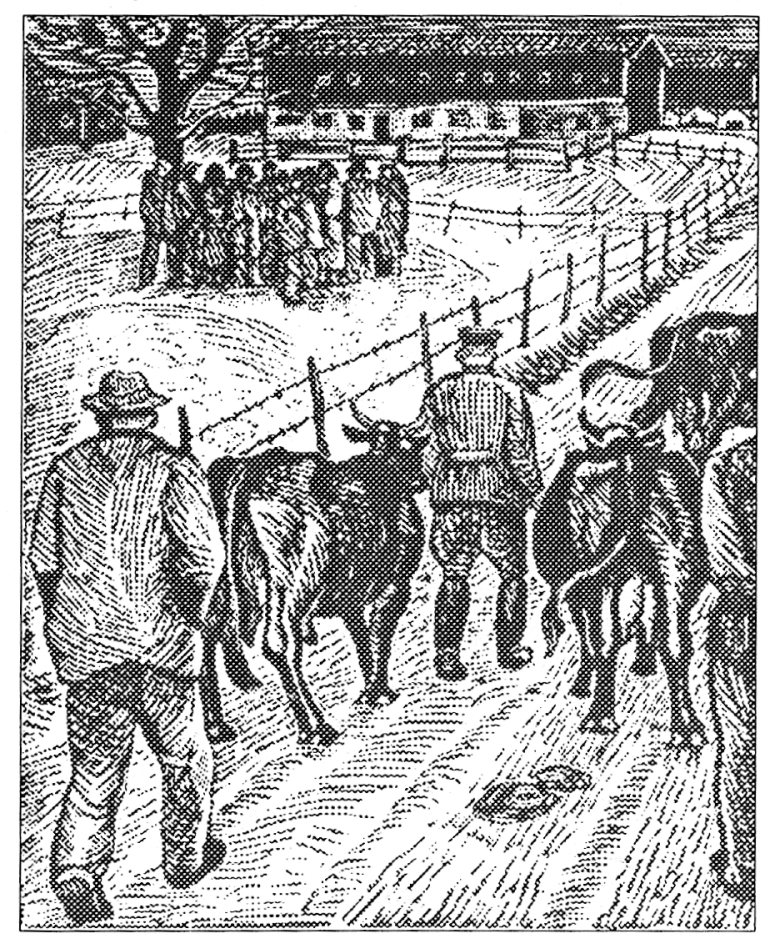

\section{Sacrificial Smoke}

\section{Volume 3 in the Holme Trilogy}

By Jan Fridegård

Translated by Robert E. Bjork

The servants of the powerful Vikings move tumultuously toward freedom in Sacrificial Smoke, the last volume of Jan Fridegård's much-acclaimed Holme trilogy. Holme leads the slave uprising that started in Land of the Wooden Gods and gathered force in People of the Dawn. But his dedication to the freedom of future generations is carried out at great personal cost. Winner of the 1987 Translation Prize of the American-Scandinavian Foundation. $\$ 24.95 \mathrm{cl}$, $\$ 9.95 \mathrm{pa}$ also in the Holme trilogy Land of Wooden Gods, $\$ 19.95 \mathrm{cl}$, \$8.95 pa People of the Dawn, $\$ 22.95 \mathrm{cl}, \$ 8.95$ pa

\section{Breaking Free}

By Ivar Lo-Johansson

Translated by Rochelle Wright

Breaking Free is indisputably a

classic of Swedish literature and has often been compared to John Steinbeck's The Grapes of Wrath. Lo-Johansson drew on his own experience in portraying the lives of workers on a large baronial estate in Sweden early in the century. His alter ego is Mikael whose subjective world of dreams contrasts dramatically with the real one of oppressive conformity and diminished opportunity. $\$ 42.50 \mathrm{cl}$

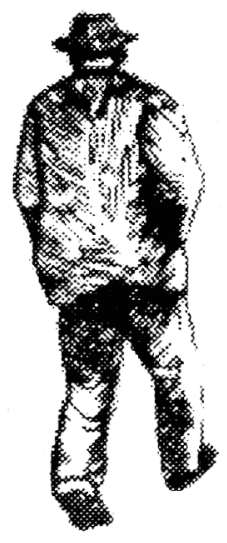

\section{The Impostor}

By Peter Seeberg

Translated by Anni Whissen

In Scandinavia The Impostor occupies the same literary niche that Catch-22 and Catcher in the Rye do in America. With great psychological intensity, the novel portrays the existential crisis of a would-be writer named Tom while it raises questions about the ethical choices made by him and others, the capacity for selfdeception, the very nature of reality. $\$ 22.95 \mathrm{cl}, \$ 7.95 \mathrm{pa}$ 